\title{
The function of TLR2 during staphylococcal diseases
}

\section{Bénédicte Fournier*}

Epithelial Pathobiology Research Unit, Department of Pathology and Laboratory Medicine, Emory University School of Medicine, Atlanta, GA, USA

\section{Edited by:}

Nelson Gekara, Umea University, Sweden

\section{Reviewed by:}

Alain Charbit, University Paris

Descartes, France

Baolin Sun, University of Science and Technology of China, China

*Correspondence:

Bénédicte Fournier, Epithelial Pathobiology Research Unit,

Department of Pathology and Laboratory Medicine, Emory

University School of Medicine, 615 Michael Street, Atlanta,

GA 30322, USA.

e-mail: bfourni@emory.edu; bfournier15@yahoo.com
Staphylococcus aureus is a versatile pathogen causing a wide range of infections. It has been a major threat both in hospitals and in the community for decades. S. aureus is a pyogenic bacterium that elicits recruitment of polymorphonuclear leukocytes (neutrophils) to the site of infection. Neutrophils are among the first immune cells to migrate to an infection site attracted by chemoattractant gradients, usually initiated in response to inflammation. Neutrophil recruitment to an inflammation and/or infection site is a sophisticated process involving their interaction with endothelial and epithelial cells through adhesion molecules. Phagocytes have various receptors to detect pathogens, and they include Toll-like receptors (TLRs). TLRs have been extensively studied over the last 10 years and it is now established that they are critical during bacterial infections. However, the function of TLRs, and more particularly TLR2, during staphylococcal infections is still debated. In this review we will consider recent findings concerning the staphylococcal ligands sensed by TLR2 and more specifically the role of staphylococcal lipoproteins in TLR2 recognition. A new concept to emerge in recent years is that staphylococcal components must be phagocytosed and digested in the phagosome to be efficiently detected by the TLR2 of professional phagocytes. Neutrophils are an essential part of the immune response to staphylococcal infections, and in the second part of this review we will therefore describe the role of TLR2 in PMN recruitment in response to staphylococcal infections.

Keywords: TLR2, ligands, phagocytosis, neutrophil, Staphylococcus aureus

\section{INTRODUCTION}

Staphylococcus aureus is a commensal, especially well-adapted to humans, also able to cause a wide range of infectious diseases from minor cutaneous infections to more severe infections such as sepsis, pneumonia, osteomyelitis, and endocarditis. It also frequently infects surgical wounds and medical implants [reviewed in Lowy (1998)]. S. aureus has become increasingly resistant to antibiotics in recent years and about $55 \%$ of healthcare-associated (formerly hospital-acquired) isolates are now resistant to methicillin (methicillin-resistant S. aureus, MRSA) [reviewed in Calfee (2012) and Gould et al. (2012)]. Mostly found in hospitals 20 years ago, MRSA strains have now spread to the community with virulent strains causing necrotizing pneumonia and other severe infections (David and Daum, 2010; Otter and French, 2011). Commensal S. aureus is found mainly in the anterior nares and about one third of the populations are permanent asymptomatic carriers. S. aureus may also colonize skin, perineum, gastrointestinal tract, and throat [reviewed in Tong et al. (2012)]. S. aureus has a formidable repertoire of virulence factors: cell-surface proteins (including protein $\mathrm{A}$ ) and numerous secreted virulence factors (for example proteolytic enzymes and cytotoxins) contribute to the development of infections by promoting bacterial adhesion, circumventing host immune defenses and causing cell or tissue damage [reviewed in Projan and Novick (1997), Foster (2005), Ben Zakour et al. (2008), Otto (2010), Cheng et al. (2011), and Edwards and Massey (2011)]. Virulence factors are crucial for development of staphylococcal infections; however, host-related determinants, such as immune competence, also play an essential role in infection (Tong et al., 2012). S. aureus induces a significant recruitment of leucocytes. Phagocytes, like most immune cells, use pattern recognition receptors (PRRs) to detect and differentiate microorganisms from self. These receptors include the Toll-like receptors (TLRs) which are transmembrane proteins capable of recognizing conserved structures of pathogens, the socalled pathogen-associated molecular patterns (PAMPs). When these pathogen molecules bind to TLRs, a cascade of protein activation results in the activation of NF- $\kappa \mathrm{B}$ and activator protein 1 , transcriptional factors that promote cytokine production [reviewed in Takeda and Akira (2004) and Oliveira-Nascimento et al. (2012)]. One of the best-characterized TLRs is TLR2 which initiates responses against a wide range of ligands (Ozinsky et al., 2000; Takeuchi et al., 2001, 2002; Sandor et al., 2003). The literature contains diverse descriptions of the function of TLRs during staphylococcal infections. We will review the most recent findings concerning the staphylococcal ligands detected by TLR2 and the role of phagocytosis in TLR2 sensing. We will also consider what is known about the contribution of TLR2 to the recruitment of neutrophils during staphylococcal infections.

\section{ROLE OF LIPOPROTEINS IN TLR2-MEDIATED SENSING OF $S$. aureus WHAT DO WE KNOW ABOUT STAPHYLOCOCCALTLR2 LIGANDS?}

TLR2 can recognize ligands with very diverse structures such as lipoproteins/lipopeptides, peptidoglycan, glycopolymers 
[lipoteichoic acid (LTA) and lipoarabinomannan], and proteins (porins, virus capsids) [reviewed in Zahringer et al. (2008) and Oliveira-Nascimento et al. (2012)]. The wide range of TLR2 ligands is partly due to its heterodimerization with co-receptors described to expand the spectrum of stimuli recognized by TLR2 without altering the signaling pathways used (Farhat et al., 2008). TLR2 associated with TLR1 senses triacyl lipopeptides/proteins (represented by the synthetic triacylated lipopeptide, Pam3-CysSer-Lys4, $\mathrm{Pam}_{3} \mathrm{CSK}_{4}$ ) (Figure 1A) whereas an association with TLR6 is required to recognize diacyl lipoproteins $\left(\mathrm{Pam}_{2} \mathrm{CSK}_{4}\right.$ or MALP2) (Ozinsky et al., 2000; Takeuchi et al., 2001, 2002; Takeda et al., 2002). Binding of $\mathrm{Pam}_{3} \mathrm{CSK}_{4}$ induces a conformational change of the ectodomains of both TLR1 and TLR2, resulting in the formation of a heterodimer. $\mathrm{Pam}_{2} \mathrm{CSK}_{4}$ does not promote this conformation and therefore does not activate TLR2-TLR1 (Jin et al., 2007). TLR2 may detect other staphylococcal PAMPs: peptidoglycan, a large polymer constituting the main component of the Gram-positive cell wall, and LTA (the counterpart of LPS in Gram-positive bacteria) [reviewed in
Fournier and Philpott (2005)] although the relevance is controversial as the concentrations of peptidoglycan and LTA necessary to trigger TLR2 are not physiological (Zahringer et al., 2008). Indeed TLR2 recognition of peptidoglycan has been debated [(Travassos et al., 2004) and reviewed in Fournier and Philpott (2005)]. It has been suggested that muramyl dipeptide, the smallest peptidoglycan structure, is detected by an intracellular PRR, Nod2 (nucleotide-binding oligomerization domain protein 2) (Girardin et al., 2003). Interestingly, it was recently shown that peptidoglycan co-localizes with both TLR2 and Nod2 after internalization. Nevertheless, the interaction of peptidoglycan with TLR2 is not dependent on Nod2 and vice-versa (Muller-Anstett et al., 2010). Furthermore, peptidoglycan potentializes the activity of other TLR ligands, including LTA and LPS (Volz et al., 2010). Thus, it is possible that peptidoglycan is a weak TLR2 ligand that contributes to host immune responses by enhancing inflammation triggered by other more potent staphylococcal ligands such as lipoproteins. In addition to TLR1 and TLR6, other accessory non-TLR molecules may also serve as TLR2 co-receptors

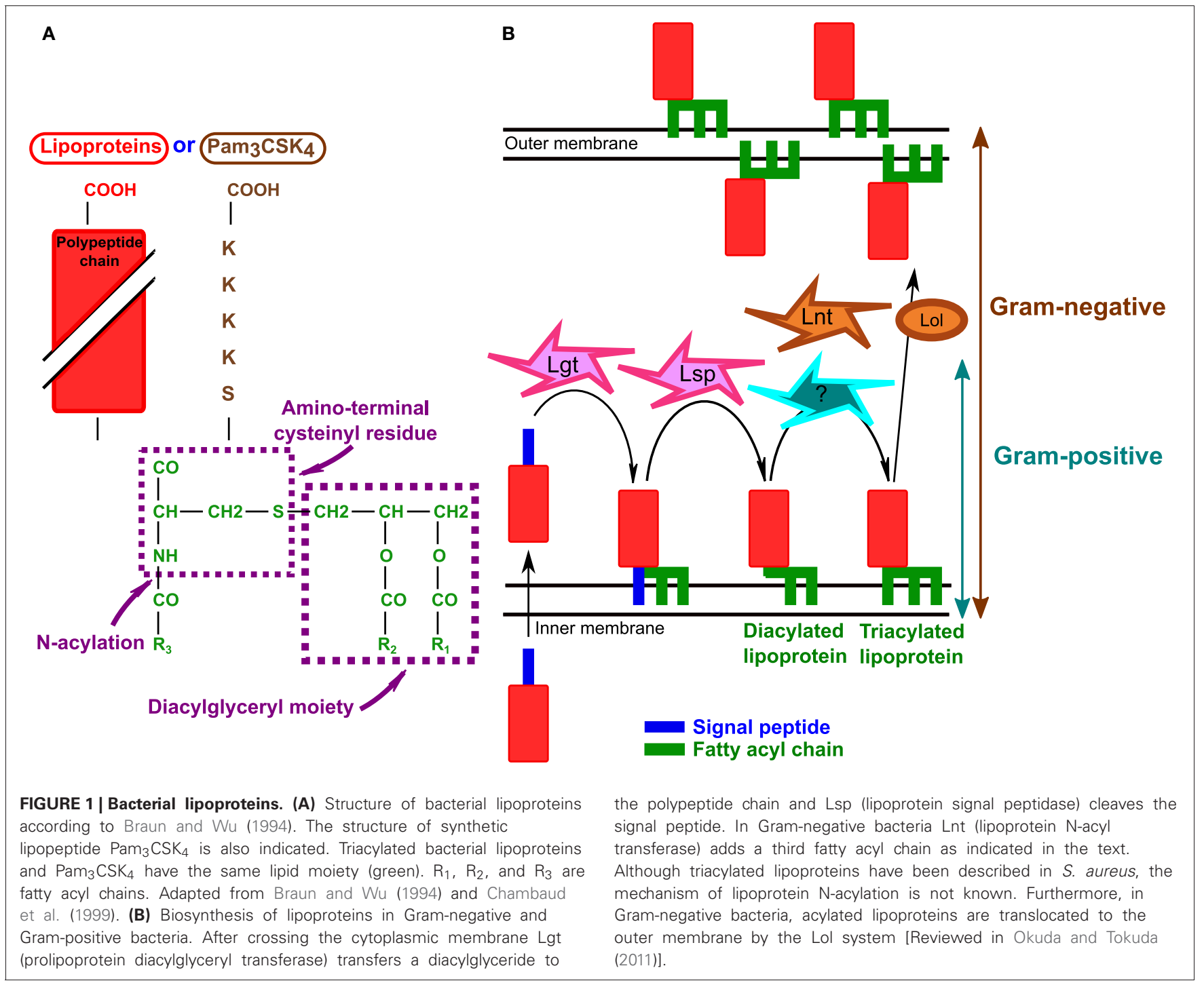


[reviewed in Oliveira-Nascimento et al. (2012)]. CD36, an integral membrane scavenger receptor, appears to have a role in LTA recognition and S. aureus phagocytosis (Hoebe et al., 2005; Stuart et al., 2005; Triantafilou et al., 2006; Baranova et al., 2008; Nilsen et al., 2008) although it is not clear how important this receptor is for the immune response against $S$. aureus (Baranova et al., 2008). CD36-deficient mice present an increased susceptibility to $S$. aureus and various TLR2 ligands including LTA and MALP2 (Hoebe et al., 2005). In contrast to other TLR2 accessory molecules, mannose-binding lectin (MBL) is a soluble humoral PRR that binds to the carbohydrate moieties of microorganisms in an EDTA-specific manner and in the case of $S$. aureus, LTA [reviewed in Ip et al. (2009)]. MBL-deficient mice are more susceptible than wild-type mice to $S$. aureus septicemia (Shi et al., 2004) and MBL has been reported to enhance $S$. aureus phagocytosis (Neth et al., 2002; Krarup et al., 2005; Ip et al., 2008). Indeed, the serum level of a wide array of cytokines ( TNF $\alpha$, RANTES, MIP-2, MCP-1, KC, IFN $\gamma$ ) is decreased in MBLdeficient mice compared to wild-type mice following $S$. aureus intravenous challenge (Ip et al., 2008). CD36 and MBL both bind to LTA but they interact independently with TLR2 (Ip et al., 2008).

Bacterial lipoproteins were first found to activate TLR2 in 1999 (Aliprantis et al., 1999) and are among the most potent staphylococcal components known to activate TLR2 (Hashimoto et al., 2006a,b). There is increasing evidence that lipoproteins play an important role in TLR2 activation by staphylococci. Lipoproteins of Gram-negative bacteria are sorted to the inner and outer membranes separated by the periplasm and are also found in the outer leaflet of the outer membrane (Figure 1B) (Okuda and Tokuda, 2011). In contrast, lipoproteins of Grampositive bacteria are only attached into the outer leaflet of the plasma membrane and are present in a subcellular space comprised between the plasma membrane and the peptidoglycan [reviewed in Hutchings et al. (2009)]. Lipoproteins are very abundant in bacteria, and make up about $2-3 \%$ of the bacterial proteome [reviewed in Hutchings et al. (2009)]. The typical structure of Gram-positive lipoprotein was determined in Braun and Wu (1994) (Figure 1A). Lipoprotein biosynthesis is a multistep process (Figure 1B). The proteins are first exported across the plasma membrane as preproteins; prolipoprotein diacylglyceryl transferase (Lgt) then transfers a diacyl glyceride to the lipobox cysteine residue in the protein signal peptide and lipoprotein signal peptidase (Lsp) cleaves the signal peptide. In Gram-negative bacteria, lipoprotein $\mathrm{N}$-acyl transferase (Lnt) adds a third fatty acyl chain to the same lipobox, thereby generating a triacylated lipoprotein [reviewed in Hutchings et al. (2009)] (Figure 1B). As Gram-positive bacteria do not possess the $\ln t$ gene, it was presumed that they contained mainly diacylated lipoproteins. However, recent data suggest that triacylated lipoproteins are also present in S. aureus: indeed staphylococcal lipoprotein SitC has three fatty acids (Kurokawa et al., 2009). SitC-stimulated macrophages produce TNF $\alpha$ and IL-6 in a TLR2- and MyD88-dependent but TLR1and TLR6-independent manner. However, SitC is not as potent as $\mathrm{Pam}_{3} \mathrm{CSK}_{4}$ (Kurokawa et al., 2009). Interestingly, sitC ${ }^{-}$strains can still activate TLR2, implicating other staphylococcal ligands including other lipoproteins in TLR2 activation (Kurokawa et al., 2009). Both diacylated and triacylated lipoproteins have been described in S. aureus (Tawaratsumida et al., 2009; Asanuma et al., 2011). A very recent study reported that lipoprotein production is modulated by environmental conditions and this may explain why both diacylated and triacylated lipropoteins have been described in S. aureus. Indeed, diacylated forms of lipoproteins are found mainly when the bacteria are in the stationary growth phase or at acidic $\mathrm{pH}$ indicating that growth conditions determine lipoprotein acylation in staphylococci (Kurokawa et al., 2012).

An lgt-deficient $S$. aureus mutant displays membraneanchored lipoproteins without the lipid groups, and the full lipoproteins are detected mainly in the culture supernatant (Stoll et al., 2005). The TLR2-dependent production of cytokines (TNFo, IL-10, IL-6, IL-8, and MIP2) in various cell types (mononuclear, epithelial, and endothelial cells) in response to this mutant was very much lower than that in response to the wild type (Stoll et al., 2005; Schmaler et al., 2009; Kang et al., 2011). However, in vivo studies with a murine model of septicemia are contradictory: in one study, the S. aureus $\lg t^{-}$mutant was more virulent than the WT strain (Bubeck Wardenburg et al., 2006), whereas another study reports lower virulence for this mutant (Schmaler et al., 2009). These various findings nevertheless indicate that staphylococcal lipoproteins are critical for the innate immune response through TLR2. However, the exact role of lipoproteins in vivo, and whether lipoproteins are indeed necessary for staphylococcal infections, remain unclear.

\section{ROLE OF PHAGOCYTOSIS IN TLR2 SENSING}

Phagocytosis of pathogens by professional phagocytes is a key step in innate immunity. Phagocyte receptors (Fc receptors, complement receptors, integrins, scavenger receptors among others) recognize bacteria opsonized with immunoglobulins, complement, or extracellular matrices e.g., fibronectin [Reviewed in Underhill and Ozinsky (2002)]. After major rearrangements of the actin cytoskeleton, phagocytes internalize bacteria (Underhill and Ozinsky, 2002). TLRs are not phagocytic receptors per se, but they are also internalized in the process and therefore participate to the link between phagocytosis and inflammatory responses by triggering the production of cytokines (Underhill and Ozinsky, 2002). Engulfed bacteria are transferred to phagosomes, which fuse with other organelles (endosomes and lysosomes) and enzymatic complexes such as NADPH oxidase. The result is a highly hydrolytic phagolysosome with reactive oxygen species that lyses bacteria and digests their components [reviewed in Underhill and Ozinsky (2002), Stuart and Ezekowitz (2005), Kinchen and Ravichandran (2008), and Nordenfelt and Tapper (2011)]. Treatment of THP-1, macrophage-like cells, with live S. aureus increases the expression of TLR2 and MyD88 (Zarember and Godowski, 2002). Intriguingly, although MyD88deficient macrophages release much less cytokines than wildtype macrophages after staphylococcal infection, TLR2-deficient macrophages produce a significant amounts of cytokines, suggesting that other receptors associated with MyD88 are involved in Staphylococcus sensing (Takeuchi et al., 2000; Lembo et al., 
2003). In 1999, a first study reported that TLRs were recruited to the phagolysosomes where they were capable of differentiating Gram-negative from Gram-positive pathogens to produce cytokines (Underhill et al., 1999). Indeed, dominant-negative inhibitor TLR2 or MyD88 introduced into macrophage-like cells (RAW 264.7) failed to produce $\mathrm{TNF} \alpha$ in response to $S$. aureus infection, whereas the wild-type gene did (Underhill et al., 1999). Other studies later suggested that there are two modes of phagosome maturation (constitutive and inducible) and TLRs including TLR2 may accelerate inducible maturation in presence of specific ligands (Blander and Medzhitov, 2004) although this is still controversial (Yates and Russell, 2005).

Several articles demonstrate that staphylococcal degradation in the phagosome is required for PAMP release and recognition by PRRs (Kapetanovic et al., 2007; Dietrich et al., 2010; Ip et al., 2010; Shimada et al., 2010; Wolf et al., 2011). Thus, phagocytosis seems to proceed in two steps. First, bacteria are recognized by TLRs at the surface of the phagocytes and this is not dependent on TLR ligands (Figure 2). Indeed, peptidoglycan from $S$. aureus strains resistant to lysozyme and from wild-type strains release similar amounts of IL-1 $\beta$ and $\mathrm{TNF} \alpha$ during the first hour post-infection (Shimada et al., 2010; Wolf et al., 2011), suggesting that peptidoglycan does not require to be degraded at this step. Second, engulfed bacteria are transferred into phagosomes and lysed. During this digestion in the phagosomes, most bacterial cell-wall components and bacterial DNA are released, resulting in materials presented to PRRs (Ip et al., 2010; Wolf et al., 2011). Cytosolic PRRs detecting these structures are either engulfed TLRs such as TLR2, cytosolic TLRs such as TLR9 (a receptor for CpG motifs in DNA), or Nod2 depending on the study (Kapetanovic et al., 2007; Wolf et al., 2011) (Figure 2). Phagocytosis and digestion of pathogens therefore amplify the immune response by presenting motifs recognized by cytosolic PRRs (Wolf et al., 2011). SitC increases intracellular TLR2 and co-localizes with TLR2 (but unlike peptidoglycan, not with Nod2) (Muller et al., 2010; Muller-Anstett et al., 2010). TLR2 and MBL have been reported to co-immunoprecipitate and also co-localize in the phagosome. Importantly, cytochalasin D, a phagocytosis inhibitor, suppresses MBL-induced TNF $\alpha$, suggesting that internalization is necessary for MLB function (Ip et al., 2008). Thus, internalization seems to be a prerequisite for full S. aureus-induced activation of TLR2, at least in professional phagocyte cells.

\section{TLR2 AND NEUTROPHIL RECRUITMENT DURING STAPHYLOCOCCAL INFECTIONS}

Polymorphonuclear cells (PMN) constitute one of the first lines of defense against pathogens, and are thus an important component of the innate immune response to staphylococcal infections. Neutrophils are equipped with a powerful arsenal of weapons capable of killing most pathogens including Staphylococcus [reviewed in Miller and Cho (2011), Fournier and Parkos (2012), and Rigby and Deleo (2012)]. Immune diseases leading to neutropenia or neutrophil dysfunction, such as defects of intracellular killing (chronic granulomatous

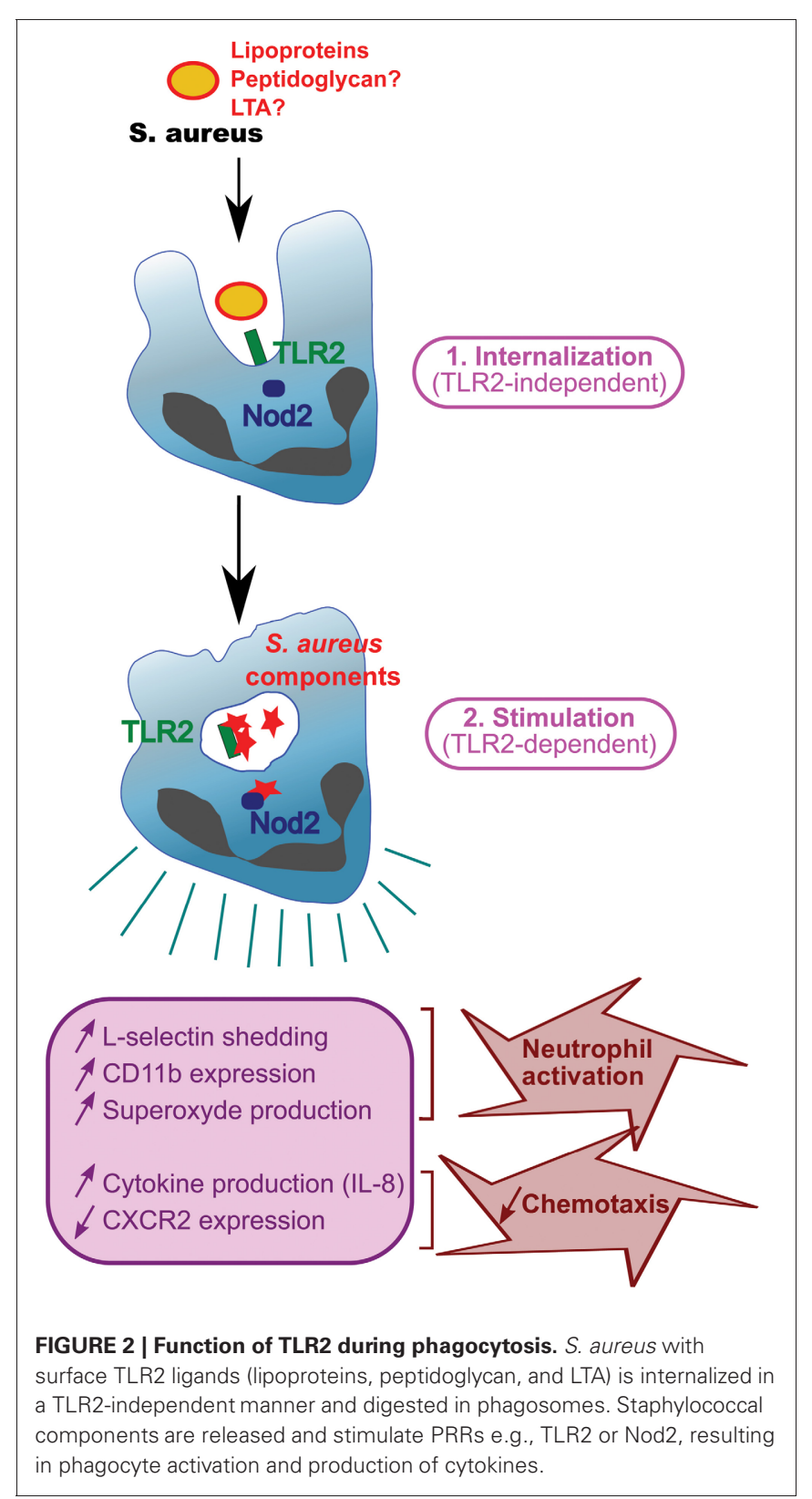

disease, myeloperoxidase deficiency, and glucose-6-phosphate dehydrogenase deficiency) and degranulation (Chediak-Higashi syndrome), or abnormal chemotaxis (leukocyte adhesion deficiency, Job's syndrome) result in recurrent staphylococcal disease [reviewed in Lakshman and Finn (2001), Spickett (2008), Rigby and Deleo (2012), and Tong et al. (2012)], highlighting the critical function of neutrophils in the immune response against S. aureus. Although not directly implicating TLR2, two interesting studies report that children with mutations in MyD88 and IRAK4, a protein kinase involved in TLR signaling (Takeda and Akira, 2004), are at high risk of developing pyogenic bacterial infections, mainly involving Gram-positive bacteria such as staphylococci (Picard et al., 2003; Von Bernuth et al., 2008). 
TLR2 is strongly expressed on leukocytes (mainly in peripheral blood, but also spleen) (Zarember and Godowski, 2002) and its expression is increased in GM-CSF- and G-CSF (granulocyte/macrophage colony-stimulating factors)-stimulated neutrophils (Kurt-Jones et al., 2002; Hayashi et al., 2003). TLR2 activation also contributes to PMN stimulation. Indeed, stimulation of human PMN with the TLR2 ligand $\mathrm{Pam}_{3} \mathrm{CSK}_{4}$ induces production of several cytokines (IL-8, MIP-1 $\alpha$, MIP$1 \beta$, MIP-3 $\alpha$, and IL-1 $\beta$ ) (Hayashi et al., 2003; Sabroe et al., 2003). Activation of TLR2 by $\mathrm{Pam}_{3} \mathrm{CSK}_{4}$ induces L-selectin shedding and increases CD11b expression both involved in PMN migration. $\mathrm{Pam}_{3} \mathrm{CSK}_{4}$ in synergy with the bacteria-derived chemoattractant formyl-methionyl-leucyl-phenylalanine (fMLF) generates superoxide (Figure 2). Interestingly, neutrophils from patients with chronic granulomatous disease presenting a defect in oxidative metabolism do not show increased CD11b and TLR2 expression upon stimulation with $\mathrm{Pam}_{3} \mathrm{CSK}_{4}$ (Kobayashi et al., 2004; Hartl et al., 2008), suggesting that oxidative metabolism is necessary for lipoprotein effect. Furthermore, TLR2 stimulation with $\mathrm{Pam}_{3} \mathrm{CSK}_{4}$ also results in increased neutrophil phagocytosis (Hayashi et al., 2003).

The relevance of TLR2-driven immune responses during staphylococcal infections and more particularly neutrophil recruitment has been recently studied. TLR2 appears to contribute to mouse survival in a model of Staphylococcus-induced septicemia, but only against intravenous challenge with $10^{7}$ bacteria (Takeuchi et al., 2000). In a murine model of staphylococcal cutaneous infection, TLR2 $2^{-/}$mice have larger lesions than wildtype mice although neutrophil recruitment was not impaired on day 1 post-infection (Molne et al., 2000; Miller et al., 2006). Work with murine models of staphylococcal skin infections, arthritis and septicemia has led to the suggestion that IL-1R, that also signals through MyD88, is more important than TLR2 for neutrophil recruitment and bacterial clearance [(Hultgren et al., 2002; Verdrengh et al., 2004; Miller et al., 2006), reviewed in Sethi and Chakraborty (2011)]. Intriguingly, neutrophil recruitment in a model of murine peritonitis is significantly lower in TLR2 $2^{-/-}$ mice than in wild-type mice after $4 \mathrm{~h}$, whereas no difference was observed after $24 \mathrm{~h}$ (Mullaly and Kubes, 2006). In contrast, the difference between wild-type and IL-1R-deficient mice in a model of septicemia appeared only after $72 \mathrm{~h}$ (Verdrengh et al., 2004). It is thus possible that TLR2 is involved in the very early immune response, whereas IL-1R may take over for subsequent PMN recruitment.

Polymicrobial infections may complicate matters further. Indeed, staphylococcal infection following a mild or severe systemic inflammatory response syndrome (SIRS) (Muckart and Bhagwanjee, 1997) generates different subsets of neutrophils: normal PMNs are found in untreated mice, whereas PMNI and -II subsets are detected in mice with mild and severe SIRS, respectively (Tsuda et al., 2004). These subsets of neutrophils differ in their capacity to activate macrophages, produce cytokines and express TLRs, TLR2 mRNA being equally abundant in all the subsets (Tsuda et al., 2004). Neutrophil recruitment is impaired during sepsis, one of the frequent manifestations of staphylococcal disease (Zou et al., 2011; Kovach and Standiford, 2012). Although the mechanisms dysregulating PMN recruitment during sepsis are multifactorial, the massive production of chemokines often contributes to neutrophil desensitization [reviewed in Kovach and Standiford (2012)]. Neutrophil recruitment is a multistep process initiated by the presence of a chemoattractant gradient that guide neutrophils to the site of inflammation [reviewed in Ley et al. (2007)]. Two receptors involved in chemoattractant detection, CXCR2 and CXCR1, are abundantly expressed at the surface of neutrophils and both recognize two neutrophil chemoattractants, CXCL-6 (or granulocyte chemotactic protein-1) and CXCL-8 (also known as IL-8) among other chemokines (Stillie et al., 2009; Stadtmann and Zarbock, 2012). High concentration of chemoattractants during sepsis dysregulates neutrophil sensing by down regulating chemoattractant receptors and activating neutrophils, resulting in impaired recruitment (Phillipson and Kubes, 2011). Indeed, peripheral neutrophils during polymicrobial sepsis exhibit only weak CXCR2 expression (Cummings et al., 1999) due in part to TLR activation by microbial ligands. Lipopeptide-treated neutrophils exhibit decreased expression of CXCR2 and CXCR1 (Hayashi et al., 2003; Sabroe et al., 2003), with the loss of CXCR2 expression being quicker and more substantial than that of CXCR1 (Sabroe et al., 2005). It has also been described that treatment with $\mathrm{Pam}_{3} \mathrm{CSK}_{4}$ and MALP2 diminishes neutrophil chemotaxis toward IL-8 or fMLF (Hayashi et al., 2003; Chin et al., 2009). Thus, decreased expression of IL- 8 receptors (CXCR-1 and CXCR-2) associated with enhanced chemoattractant production during sepsis may impair perception of chemoattractants by PMN and thereby contribute to defective PMN chemotaxis (Hayashi et al., 2003) (Figure 2). TLR2 activation by lipopeptides $24 \mathrm{~h}$ after a low-dose staphylococcal infection results in lethal sepsis with increased bacterial load and a very large decrease of neutrophil numbers (Navarini et al., 2009). Furthermore, TLR2deficient mice with acute polymicrobial peritonitis, induced by cecal ligation and puncture, exhibit enhanced neutrophil migration, resulting in a decreased bacterial load and serum cytokine production (Alves-Filho et al., 2009). Thus, TLR2 participates actively to neutrophil stimulation and recruitment during staphylococcal infections.

\section{CONCLUSION}

Staphylococcal diseases have become a significant health issue, and there is a dearth of appropriate antibiotics to treat them. The role of PRRs, including TLR2, during these infections is thus of particular interest. Our knowledge of the staphylococcal components involved in TLR2 recognition has improved substantially, and lipoproteins have been shown to be among the most potent TLR2 ligands in S. aureus. The environmentdependent regulation of lipoprotein acylation necessary for detection by TLR2 complicates the issue, and raises questions about how this regulation may modulate host immune responses in vivo. Although there is a consensus concerning the role of phagocyte TLR2, stimulated with staphylococcal ligands in vitro, reports on the role of lipoproteins in murine staphylococcal infections in vivo are more discordant. Further in vivo studies are therefore required to elucidate lipoprotein function in the immune response against $S$. aureus. TLR2 is also a major player in staphylococcal disease through its 
diverse roles in various professional phagocyte functions: PMN stimulation and adhesion molecule expression, chemotaxis and chemoattractant receptor expression, and phagocytosis and ligand detection (Figure 2).

\section{REFERENCES}

Aliprantis, A. O., Yang, R. B., Mark, M. R., Suggett, S., Devaux, B., Radolf, J. D., et al. (1999). Cell activation and apoptosis by bacterial lipoproteins through toll-like receptor-2. Science 285, 736-739.

Alves-Filho, J. C., Freitas, A., Souto, F. O., Spiller, F., Paula-Neto, H., Silva, J. S., et al. (2009). Regulation of chemokine receptor by Toll-like receptor 2 is critical to neutrophil migration and resistance to polymicrobial sepsis. Proc. Natl. Acad. Sci. U.S.A. 106, 4018-4023.

Asanuma, M., Kurokawa, K., Ichikawa, R., Ryu, K. H., Chae, J. H., Dohmae, N., et al. (2011). Structural evidence of alpha-aminoacylated lipoproteins of Staphylococcus aureus. FEBS J. 278, 716-728.

Baranova, I. N., Kurlander, R., Bocharov, A. V., Vishnyakova, T. G., Chen, Z., Remaley, A. T., et al. (2008). Role of human CD36 in bacterial recognition, phagocytosis, and pathogen-induced JNKmediated signaling. J. Immunol. 181, 7147-7156.

Ben Zakour, N. L., Guinane, C. M., and Fitzgerald, J. R. (2008). Pathogenomics of the staphylococci: insights into niche adaptation and the emergence of new virulent strains. FEMS Microbiol. Lett. 289, $1-12$.

Blander, J. M., and Medzhitov, R. (2004). Regulation of phagosome maturation by signals from toll-like receptors. Science 304, 1014-1018.

Braun, V., and Wu, H. C. (1994). "Lipoproteins, structure, function, biosynthesis and model for protein export," in New Comprehensive Biochemistry (Bacterial cell wall, volume 27), eds J.-M. Ghuysen and R. Hakenbeck (Amsterdam: Elsevier Science), 319-341.

Bubeck Wardenburg, J., Williams, W. A., and Missiakas, D. (2006). Host defenses against Staphylococcus aureus infection require recognition of bacterial lipoproteins. Proc. Natl. Acad. Sci. U.S.A. 103, 13831-13836.

Calfee, D. P. (2012). Methicillinresistant Staphylococcus aureus and vancomycin-resistant enterococci, and other Gram-positives in healthcare. Curr. Opin. Infect. Dis. 25, 385-394.

Chambaud, I., Wroblewski, H., and Blanchard, A. (1999). Interactions between mycoplasma lipoproteins and the host immune system. Trends Microbiol. 7, 493-499.

Cheng, A. G., Dedent, A. C., Schneewind, O., and Missiakas, D. (2011). A play in four acts: Staphylococcus aureus abscess formation. Trends Microbiol. 19, 225-232.

Chin, A. C., Fournier, B., Peatman, E. J., Reaves, T. A., Lee, W. Y., and Parkos, C. A. (2009). CD47 and TLR-2 cross-talk regulates neutrophil transmigration. J. Immunol. 183, 5957-5963.

Cummings, C. J., Martin, T. R., Frevert, C. W., Quan, J. M., Wong, V. A., Mongovin, S. M., et al. (1999). Expression and function of the chemokine receptors CXCR1 and CXCR2 in sepsis. J. Immunol. 162, 2341-2346.

David, M. Z., and Daum, R. S. (2010). Community-associated methicillin-resistant Staphylococcus aureus: epidemiology and clinical consequences of an emerging epidemic. Clin. Microbiol. Rev. 23, 616-687.

Dietrich, N., Lienenklaus, S., Weiss, S., and Gekara, N. O. (2010). Murine toll-like receptor 2 activation induces type I interferon responses from endolysosomal compartments. PLoS ONE 5:e10250. doi: 10.1371/journal.pone.0010250

Edwards, A. M., and Massey, R. C. (2011). How does Staphylococcus aureus escape the bloodstream? Trends Microbiol. 19, 184-190.

Farhat, K., Riekenberg, S., Heine, H., Debarry, J., Lang, R., Mages, J., et al. (2008). Heterodimerization of TLR2 with TLR1 or TLR6 expands the ligand spectrum but does not lead to differential signaling. J. Leukoc. Biol. 83, 692-701.

Foster, T. J. (2005). Immune evasion by staphylococci. Nat. Rev. Microbiol. 3 , 948-958.

Fournier, B., and Philpott, D. J. (2005). Recognition of Staphylococcus aureus by the innate immune system. Clin. Microbiol. Rev. 18, 521-540.

Fournier, B. M., and Parkos, C. A. (2012). The role of neutrophils during intestinal inflammation. Mucosal Immunol. 5, 354-366.

Girardin, S. E., Boneca, I. G., Viala, J., Chamaillard, M., Labigne, A., Thomas, G., et al. (2003). Nod2

\section{ACKNOWLEDGMENTS}

The author acknowledges funding from a Senior Research Award from the Crohn's and Colitis Foundation of America (CCFA) sponsored by the Rodenberry Foundation.

is a general sensor of peptidoglycan through muramyl dipeptide (MDP) detection. J. Biol. Chem. 278, 8869-8872.

Gould, I. M., David, M. Z., Esposito, S., Garau, J., Lina, G., Mazzei, T. et al. (2012). New insights into meticillin-resistant Staphylococcus aureus (MRSA) pathogenesis, treatment and resistance. Int. J. Antimicrob. Agents 39, 96-104.

Hartl, D., Lehmann, N., Hoffmann, F., Jansson, A., Hector, A., Notheis, G., et al. (2008). Dysregulation of innate immune receptors on neutrophils in chronic granulomatous disease. J. Allergy Clin. Immunol. 121, 375-382.e9.

Hashimoto, M., Tawaratsumida, K. Kariya, H., Aoyama, K., Tamura, T., and Suda, Y. (2006a). Lipoprotein is a predominant Toll-like receptor 2 ligand in Staphylococcus aureus cell wall components. Int. Immunol. 18, 355-362.

Hashimoto, M., Tawaratsumida, K. Kariya, H., Kiyohara, A., Suda, Y., Krikae, F., et al. (2006b). Not lipoteichoic acid but lipoproteins appear to be the dominant immunobiologically active compounds in Staphylococcus aureus. J. Immunol. 177, 3162-3169.

Hayashi, F., Means, T. K., and Luster, A D. (2003). Toll-like receptors stimulate human neutrophil function. Blood 102, 2660-2669.

Hoebe, K., Georgel, P., Rutschmann, S. Du, X., Mudd, S., Crozat, K., et al. (2005). CD36 is a sensor of diacylglycerides. Nature 433, 523-527.

Hultgren, O. H., Svensson, L., and Tarkowski, A. (2002). Critical role of signaling through IL-1 receptor for development of arthritis and sepsis during Staphylococcus aureus infection. J. Immunol. 168, 5207-5212.

Hutchings, M. I., Palmer, T., Harrington, D. J., and Sutcliffe, I. C. (2009). Lipoprotein biogenesis in Gram-positive bacteria: knowing when to hold 'em, knowing when to fold 'em. Trends Microbiol. 17, 13-21.

Ip, W. K., Sokolovska, A., Charriere, G. M., Boyer, L., Dejardin, S. Cappillino, M. P., et al. (2010). Phagocytosis and phagosome acidification are required for pathogen processing and MyD88-dependent responses to Staphylococcus aureus. J. Immunol. 184, 7071-7081.
Ip, W. K., Takahashi, K., Ezekowitz, R. A., and Stuart, L. M. (2009). Mannose-binding lectin and innate immunity. Immunol. Rev. 230, 9-21.

Ip, W. K., Takahashi, K., Moore, K. J., Stuart, L. M., and Ezekowitz, R. A. (2008). Mannose-binding lectin enhances Toll-like receptors 2 and 6 signaling from the phagosome. J. Exp. Med. 205, 169-181.

Jin, M. S., Kim, S. E., Heo, J. Y., Lee, M. E., Kim, H. M., Paik, S. G., et al. (2007). Crystal structure of the TLR1-TLR2 heterodimer induced by binding of a tri-acylated lipopeptide. Cell 130, 1071-1082.

Kang, H. J., Ha, J. M., Kim, H. S., Lee, H., Kurokawa, K., and Lee, B. L. (2011). The role of phagocytosis in IL-8 production by human monocytes in response to lipoproteins on Staphylococcus aureus. Biochem. Biophys. Res. Commun. 406, 449-453.

Kapetanovic, R., Nahori, M. A., Balloy, V., Fitting, C., Philpott, D. J., Cavaillon, J. M., et al. (2007). Contribution of phagocytosis and intracellular sensing for cytokine production by Staphylococcus aureus-activated macrophages. Infect. Immun. 75, 830-837.

Kinchen, J. M., and Ravichandran, K. S. (2008). Phagosome maturation: going through the acid test. Nat. Rev. Mol. Cell Biol. 9, 781-795.

Kobayashi, S. D., Voyich, J. M. Braughton, K. R., Whitney, A. R., Nauseef, W. M., Malech, H. L., et al. (2004). Gene expression profiling provides insight into the pathophysiology of chronic granulomatous disease. J. Immunol. 172, 636-643.

Kovach, M. A., and Standiford, T. J. (2012). The function of neutrophils in sepsis. Curr. Opin. Infect. Dis. 25, 321-327.

Krarup, A., Sorensen, U. B., Matsushita, M., Jensenius, J. C., and Thiel, S. (2005). Effect of capsulation of opportunistic pathogenic bacteria on binding of the pattern recognition molecules mannan-binding lectin, L-ficolin, and $\mathrm{H}$-ficolin. Infect. Immun. 73, 1052-1060.

Kurokawa, K., Kim, M. S., Ichikawa, R., Ryu, K. H., Dohmae, N., Nakayama, H., et al. (2012). Environmentmediated accumulation of diacyl lipoproteins over their triacyl counterparts in Staphylococcus aureus. J. Bacteriol. 194, 3299-3306. 
Kurokawa, K., Lee, H., Roh, K. B., Asanuma, M., Kim, Y. S., Nakayama, H., et al. (2009). The triacylated ATP binding cluster transporter substrate-binding lipoprotein of Staphylococcus aureus functions as a native ligand for toll-like receptor 2. J. Biol. Chem. 284, 8406-8411.

Kurt-Jones, E. A., Mandell, L., Whitney, C., Padgett, A., Gosselin, K., Newburger, P. E., et al. (2002). Role of toll-like receptor 2 (TLR2) in neutrophil activation: GM-CSF enhances TLR2 expression and TLR2-mediated interleukin 8 responses in neutrophils. Blood 100, 1860-1868.

Lakshman, R., and Finn, A. (2001). Neutrophil disorders and their management. J. Clin. Pathol. 54, 7-19.

Lembo, A., Kalis, C., Kirschning, C. J., Mitolo, V., Jirillo, E., Wagner, H., et al. (2003). Differential contribution of Toll-like receptors 4 and 2 to the cytokine response to Salmonella enterica serovar Typhimurium and Staphylococcus aureus in mice. Infect. Immun. 71, 6058-6062.

Ley, K., Laudanna, C., Cybulsky, M. I., and Nourshargh, S. (2007). Getting to the site of inflammation: the leukocyte adhesion cascade updated. Nat. Rev. Immunol. 7, 678-689.

Lowy, F. D. (1998). Staphylococcus aureus infections. N. Engl. J. Med. 339, 520-532.

Miller, L. S., and Cho, J. S. (2011). Immunity against Staphylococcus aureus cutaneous infections. Nat. Rev. Immunol. 11, 505-518.

Miller, L. S., O'Connell, R. M., Gutierrez, M. A., Pietras, E. M., Shahangian, A., Gross, C. E., et al. (2006). MyD88 mediates neutrophil recruitment initiated by IL-1R but not TLR2 activation in immunity against Staphylococcus aureus. Immunity 24, 79-91.

Molne, L., Verdrengh, M., and Tarkowski, A. (2000). Role of neutrophil leukocytes in cutaneous infection caused by Staphylococcus aureus. Infect. Immun. 68, 6162-6167.

Muckart, D. J., and Bhagwanjee, S. (1997). American College of Chest Physicians/Society of Critical Care Medicine Consensus Conference definitions of the systemic inflammatory response syndrome and allied disorders in relation to critically injured patients. Crit. Care Med. 25, 1789-1795.

Mullaly, S. C., and Kubes, P. (2006). The role of TLR2 in vivo following challenge with Staphylococcus aureus and prototypic ligands. J. Immunol. 177, 8154-8163.

Muller, P., Muller-Anstett, M., Wagener, J., Gao, Q., Kaesler, S., Schaller, M., et al. (2010). The Staphylococcus aureus lipoprotein $\mathrm{SitC}$ colocalizes with Toll-like receptor 2 (TLR2) in murine keratinocytes and elicits intracellular TLR2 accumulation. Infect. Immun. 78, 4243-4250.

Muller-Anstett, M. A., Muller, P., Albrecht, T., Nega, M., Wagener, J., Gao, Q., et al. (2010). Staphylococcal peptidoglycan co-localizes with Nod2 and TLR2 and activates innate immune response via both receptors in primary murine keratinocytes. PLOS ONE 5:e13153. doi: 10.1371/journal.pone.0013153

Navarini, A. A., Lang, K. S., Verschoor, A., Recher, M., Zinkernagel, A. S., Nizet, V., et al. (2009). Innate immune-induced depletion of bone marrow neutrophils aggravates systemic bacterial infections. Proc. Natl. Acad. Sci. U.S.A. 106, 7107-7112.

Neth, O., Jack, D. L., Johnson, M., Klein, N. J., and Turner, M. W. (2002). Enhancement of complement activation and opsonophagocytosis by complexes of mannose-binding lectin with mannose-binding lectin-associated serine protease after binding to Staphylococcus aureus. J. Immunol. 169, 4430-4436.

Nilsen, N. J., Deininger, S., Nonstad, U., Skjeldal, F., Husebye, H., Rodionov, D., et al. (2008). Cellular trafficking of lipoteichoic acid and Toll-like receptor 2 in relation to signaling: role of CD14 and CD36. J. Leukoc. Biol. 84, 280-291.

Nordenfelt, P., and Tapper, H. (2011). Phagosome dynamics during phagocytosis by neutrophils. J. Leukoc. Biol. 90, 271-284.

Okuda, S., and Tokuda, H. (2011). Lipoprotein sorting in bacteria. Annu. Rev. Microbiol. 65, 239-259.

Oliveira-Nascimento, L., Massari, P., and Wetzler, L. M. (2012). The role of TLR2 in infection and immunity. Front. Immun. 3:79. doi: 10.3389/fimmu.2012.00079

Otter, J. A., and French, G. L. (2011). Community-associated meticillinresistant Staphylococcus aureus strains as a cause of healthcareassociated infection. J. Hosp. Infect. 79, 189-193.

Otto, M. (2010). Basis of virulence in community-associated methicillinresistant Staphylococcus aureus. Annu. Rev. Microbiol. 64, 143-162.

Ozinsky, A., Underhill, D. M., Fontenot, J. D., Hajjar, A. M.,
Smith, K. D., Wilson, C. B., et al. (2000). The repertoire for pattern recognition of pathogens by the innate immune system is defined by cooperation between toll-like receptors. Proc. Natl. Acad. Sci. U.S.A. 97, 13766-13771.

Phillipson, M., and Kubes, P. (2011). The neutrophil in vascular inflammation. Nat. Med. 17, 1381-1390.

Picard, C., Puel, A., Bonnet, M., Ku, C. L., Bustamante, J., Yang, K., et al. (2003). Pyogenic bacterial infections in humans with IRAK-4 deficiency. Science 299, 2076-2079.

Projan, S. J., and Novick, R. P. (1997) "The molecular basis of pathogenicity," in The Staphylococci in Human Disease, eds K. B. Crossley and G. L. Archer (New York, NY: Churchill Livingstone), 55-81.

Rigby, K. M., and Deleo, F. R. (2012). Neutrophils in innate host defense against Staphylococcus aureus infections. Semin. Immunopathol. 34 237-259.

Sabroe, I., Jones, E. C., Whyte, M. K., and Dower, S. K. (2005). Regulation of human neutrophil chemokine receptor expression and function by activation of Toll-like receptors 2 and 4. Immunology 115 90-98.

Sabroe, I., Prince, L. R., Jones, E. C. Horsburgh, M. J., Foster, S. J., Vogel, S. N., et al. (2003). Selective roles for Toll-like receptor (TLR) 2 and TLR4 in the regulation of neutrophil activation and life span. J. Immunol. 170, 5268-5275.

Sandor, F., Latz, E., Re, F., Mandell, L. Repik, G., Golenbock, D. T., et al. (2003). Importance of extra- and intracellular domains of TLR1 and TLR2 in NFkappa B signaling. J. Cell Biol. 162, 1099-1110.

Schmaler, M., Jann, N. J., Ferracin, F., Landolt, L. Z., Biswas, L., Gotz, F., et al. (2009). Lipoproteins in Staphylococcus aureus mediate inflammation by TLR2 and iron-dependent growth in vivo. J. Immunol. 182, 7110-7118.

Sethi, S., and Chakraborty, T. (2011). Role of TLR-/NLR-signaling and the associated cytokines involved in recruitment of neutrophils in murine models of Staphylococcus aureus infection. Virulence 2, 316-328.

Shi, L., Takahashi, K., Dundee, J., Shahroor-Karni, S., Thiel, S., Jensenius, J. C., et al. (2004). Mannose-binding lectin-deficient mice are susceptible to infection with Staphylococcus aureus. J. Exp. Med. 199, 1379-1390.

Shimada, T., Park, B. G., Wolf, A. J., Brikos, C., Goodridge, H. S., Becker,
C. A., et al. (2010). Staphylococcus aureus evades lysozyme-based peptidoglycan digestion that links phagocytosis, inflammasome activation, and IL-1beta secretion. Cell Host Microbe 7, 38-49.

Spickett, G. P. (2008). Immune deficiency disorders involving neutrophils. J. Clin. Pathol. 61, 1001-1005.

Stadtmann, A., and Zarbock, A. (2012). CXCR2: from bench to bedside. Front. Immun. 3:263. doi: 10.3389/fimmu.2012.00263

Stillie, R., Farooq, S. M., Gordon, J. R., and Stadnyk, A. W. (2009). The functional significance behind expressing two IL-8 receptor types on PMN. J. Leukoc. Biol. 86, 529-543.

Stoll, H., Dengjel, J., Nerz, C., and Gotz, F. (2005). Staphylococcus aureus deficient in lipidation of prelipoproteins is attenuated in growth and immune activation. Infect. Immun. 73, 2411-2423.

Stuart, L. M., Deng, J., Silver, J. M., Takahashi, K., Tseng, A. A., Hennessy, E. J., et al. (2005). Response to Staphylococcus aureus requires CD36-mediated phagocytosis triggered by the COOH-terminal cytoplasmic domain. J. Cell Biol. 170, 477-485.

Stuart, L. M., and Ezekowitz, R. A. (2005). Phagocytosis: elegant complexity. Immunity 22, 539-550.

Takeda, K., and Akira, S. (2004). TLR signaling pathways. Semin. Immunol. 16, 3-9.

Takeda, K., Takeuchi, O., and Akira, S. (2002). Recognition of lipopeptides by Toll-like receptors. J. Endotoxin Res. 8, 459-463.

Takeuchi, O., Hoshino, K., and Akira, S. (2000). Cutting edge: TLR2deficient and MyD88-deficient mice are highly susceptible to Staphylococcus aureus infection. J. Immunol. 165, 5392-5396.

Takeuchi, O., Kawai, T., Muhlradt, P. F., Morr, M., Radolf, J. D., Zychlinsky, A., et al. (2001). Discrimination of bacterial lipoproteins by Tolllike receptor 6. Int. Immunol. 13, 933-940.

Takeuchi, O., Sato, S., Horiuchi, T., Hoshino, K., Takeda, K., Dong, Z., et al. (2002). Cutting edge: role of Toll-like receptor 1 in mediating immune response to microbial lipoproteins. J. Immunol. 169, 10-14.

Tawaratsumida, K., Furuyashiki, M., Katsumoto, M., Fujimoto, Y., Fukase, K., Suda, Y., et al. (2009). Characterization of N-terminal structure of TLR2-activating lipoprotein in Staphylococcus 
aureus. J. Biol. Chem. 284, 9147-9152.

Tong, S. Y., Chen, L. F., and Fowler, V. G. Jr. (2012). Colonization, pathogenicity, host susceptibility, and therapeutics for Staphylococcus aureus: what is the clinical relevance? Semin. Immunopathol. 34, 185-200.

Travassos, L. H., Girardin, S. E., Philpott, D. J., Blanot, D., Nahori, M. A., Werts, C., et al. (2004). Toll-like receptor 2-dependent bacterial sensing does not occur via peptidoglycan recognition. $E M B O$ Rep. 10, 1000-1006.

Triantafilou, M., Gamper, F. G., Haston, R. M., Mouratis, M. A., Morath, S., Hartung, T., et al. (2006). Membrane sorting of toll-like receptor (TLR)-2/6 and TLR2/1 heterodimers at the cell surface determines heterotypic associations with CD36 and intracellular targeting. J. Biol. Chem. 281, 31002-31011.

Tsuda, Y., Takahashi, H., Kobayashi, M., Hanafusa, T., Herndon, D. N., and Suzuki, F. (2004). Three different neutrophil subsets exhibited in mice with different susceptibilities to infection by methicillin-resistant Staphylococcus aureus. Immunity 21 , 215-226.

Underhill, D. M., and Ozinsky, A. (2002). Phagocytosis of microbes: complexity in action. Annu. Rev. Immunol. 20, 825-852.

Underhill, D. M., Ozinsky, A., Hajjar, A. M., Stevens, A., Wilson, C. B., Bassetti, M., et al. (1999). The Toll-like receptor 2 is recruited to macrophage phagosomes and discriminates between pathogens. Nature 401, 811-815.

Verdrengh, M., Thomas, J. A., and Hultgren, O. H. (2004). IL-1 receptor-associated kinase 1 mediates protection against Staphylococcus aureus infection. Microbes Infect. 6, 1268-1272.

Volz, T., Nega, M., Buschmann, J., Kaesler, S., Guenova, E., Peschel, A., et al. (2010). Natural Staphylococcus aureus-derived peptidoglycan fragments activate NOD2 and act as potent costimulators of the innate immune system exclusively in the presence of TLR signals. FASEB $\mathrm{J}$. 24, 4089-4102.

Von Bernuth, H., Picard, C., Jin, Z., Pankla, R., Xiao, H., Ku, C. L., et al.
(2008). Pyogenic bacterial infections in humans with MyD88 deficiency. Science 321, 691-696.

Wolf, A. J., Arruda, A., Reyes, C. N., Kaplan, A. T., Shimada, T., Shimada, K., et al. (2011). Phagosomal degradation increases TLR access to bacterial ligands and enhances macrophage sensitivity to bacteria. J. Immunol. 187, 6002-6010.

Yates, R. M., and Russell, D. G (2005). Phagosome maturation proceeds independently of stimulation of toll-like receptors 2 and 4 . Immunity 23, 409-417.

Zahringer, U., Lindner, B., Inamura, S., Heine, H., and Alexander, C. (2008). TLR2- promiscuous or specific? A critical re-evaluation of a receptor expressing apparent broad specificity. Immunobiology 213, 205-224.

Zarember, K. A., and Godowski, P. J. (2002). Tissue expression of human Toll-like receptors and differential regulation of Toll-like receptor mRNAs in leukocytes in response to microbes, their products, and cytokines. J. Immunol. $168,554-561$.

Zou, L., Feng, Y., Zhang, M., Li, Y., and Chao, W. (2011).
Nonhematopoietic toll-like receptor 2 contributes to neutrophil and cardiac function impairment during polymicrobial sepsis. Shock 36 , 370-380.

Conflict of Interest Statement: The author declares that the research was conducted in the absence of any commercial or financial relationships that could be construed as a potential conflict of interest.

Received: 18 September 2012; paper pending published: 08 October 2012; accepted: 11 December 2012; published online: 04 January 2013.

Citation: Fournier B (2013) The function of TLR2 during staphylococcal diseases. Front. Cell. Inf. Microbio. 2:167. doi: 10.3389/fcimb.2012.00167

Copyright (c) 2013 Fournier. This is an open-access article distributed under the terms of the Creative Commons Attribution License, which permits use, distribution and reproduction in other forums, provided the original authors and source are credited and subject to any copyright notices concerning any thirdparty graphics etc. 